\title{
Interpretação do patrimônio, turismo e gestão de áreas protegidas: algumas aproximações
}

\section{Heritage, tourism and management interpretation of protected areas: some approaches}

\author{
Andrés Burgos Delgado (BURGOS DELGADO, A.) \\ Araceli Serantes Pazos (SERANTES PAZOS, A.) ${ }^{* * *}$
}

\begin{abstract}
RESUMO - A Interpretação do Patrimônio é um processo e instrumento de comunicação estratégica que pode favorecer a gestão das áreas protegidas, por que facilita que as pessoas descubram o significado dos lugares e atrativos que visitam, produzindo conexões emocionais e intelectuais entre os visitantes e o espaço. Ademais, apresenta-se como uma boa oportunidade de valorização da identidade local e inclusão social, uma interessante ferramenta educativa, e um atrativo incorporado à oferta turística, acrescentando valor à experiência e vivência do visitante. Com esta perspectiva, e a partir da análise bibliográfica, este trabalho desenvolve uma exploração teórica e metodológica da interpretação do patrimônio, com a intenção de refletir sobre a pertinência e eficácia da sua prática e incorporação no planejamento turístico de áreas protegidas, como estratégia que ajuda a conciliar a conservação, o desenvolvimento local e o turismo desde a perspectiva da sustentabilidade.
\end{abstract}

Palavras-chave: Interpretação do patrimônio; Áreas protegidas; Turismo sustentável; Planejamento interpretativo; Comunicação estratégica.

ABSTRACT - Heritage interpretation is a strategic communication process and tool that can facilitate the management of protected areas because it enables people to discover the meaning of places and attractions they visit, creating emotional and intellectual connections between visitors and the environment. Furthermore, it is a good opportunity to give value to local identity and social inclusion, an interesting educational strategy and an attraction incorporated in the many offers made to tourists, adding value to the visitor's perceptual experiences. Under this perspective and from a literature review, this paper develops a theoretical and methodological exploration of heritage interpretation aiming to reflect on the relevance and effectiveness of its practice

\footnotetext{
* Graduação em Biologia pela Universidade de Santiago de Compostela (Espanha). Mestrando em Desenvolvimento Sustentável pelo Centro de Desenvolvimento Sustentável - Universidade de Brasília (UNB). Consultor em Uso Público em Áreas Protegidas e Turismo Sustentável. Membro do Laboratório de Estudos de Turismo e Sustentabilidade (CDS/UnB) e Membro da Associação para a Interpretação do Patrimônio (AIP/Espanha). Endereço para correspondência: Centro de Desenvolvimento Sustentável CDS, Módulo “C”, Campus Darcy Ribeiro - Gleba A - Asa Norte. CEP 70904-970 - Brasília - Distrito Federal (Brasil). Telefones: (61) 3107-6000/6001 - Fax: (61) 3107-5972. E-mail: anburgosdelgado@unb.br

** Graduação em Filosofia e Ciências da Educação pela Universidade de Santiago de Compostela (Espanha). Doutora em Inovação e Pesquisa Educativa pela Universidade da Coruña (Espanha). Professora de Educação ambiental e cultura da sustentabilidade na Universidade da Coruña. Membro da Sociedade Ibero-americana de Pedagogia Social e Membro da Associação para a Interpretação do Patrimônio (AIP/Espanha). Endereço para correspondência: Faculdade de Ciências da Educação / Departamento de Pedagogia e Didática - Universidade da Coruña. Campus Elviña, CP 15071 - A Coruña (Espanha). Telefones: +55 981167000 Ext.: 4686. E-mail: boli@udc.es
} 
and its incorporation in the tourism planning of protected areas as a strategy that helps to reconcile the conservation, the local development and tourism from the perspective of sustainability.

Key words: Heritage interpretation; Protected areas; Sustainable tourism; Interpretive planning; Strategy communication. 


\title{
1 INTRODUÇÃO
}

A interpretação do patrimônio (IP) é uma técnica criativa de comunicação estratégica, uma forma planejada e consciente de dirigir mensagens, desenhada para que as pessoas conheçam de maneira significativa seu patrimônio e se convertam em seus protetores e defensores. Já ao final dos anos 60, Freeman Tilden, um dos precursores da interpretação, se referia a esta disciplina como:

\begin{abstract}
Uma atividade educacional que objetiva revelar significados e inter-relações mediante a utilização de objetos originais, de experiências de primeira mão e por meios ilustrativos, ao invés de simplesmente comunicar informações fatuais (TILDEN, 2006, p. 35). ${ }^{1}$
\end{abstract}

Mais recentemente, a Associação para a Interpretação do Patrimônio (AIP) $)^{2}$ a definirá como "a arte de revelar in situ o significado do legado natural, cultural ou histórico, ao público que visita esses lugares em seu tempo livre” (AIP, 1999).

A IP possui uma ampla gama de pautas e diretrizes metodológicas para a comunicação com o público, dirigidas à apresentação do patrimônio e orientadas à transmissão de uma mensagem que transcenda o simples fato da visita. Permite entender o que vale a pena entender e "ajuda a criar uma sensação de lugar" (BROCHU; MERRIMAN, 2002, p. 21). Os programas de comunicação interpretativa podem ser apresentados mediante muitos meios, normalmente classificados em impessoais (sem serviços de guias-intérpretes, como placas, folders, trilhas autoguiadas, e demais elementos que não necessitam da assistência de uma pessoa real) ou pessoais (como visitas e trilhas guiadas, onde uma pessoa interpreta para as outras) (SERANTES, 2010). Em seu esforço comunicativo, a interpretação do patrimônio utiliza algumas ferramentas da publicidade, tais como a persuasão emocional (TORRES, 2007), emitindo sugestões e sensações que conectem diretamente com as emoções inconscientes, de modo a seduzir para fomentar um espírito crítico e provocar comportamentos pró-ambientais e conservacionistas.

\footnotetext{
${ }^{1}$ As traduções de excertos citados foram feitas pelos autores do artigo.

${ }^{2}$ A Associação para a Interpretação do Patrimônio (AIP) é uma entidade sem fins lucrativos, com sede na Espanha, que promove o desenvolvimento profissional e técnico da interpretação. Disponível em: $<$ http://www.interpretaciondelpatrimonio.com/>.
} 
O público destinatário da IP é heterogêneo e não está sujeito a nenhum tipo de obrigação quando se aproxima a um atrativo natural ou cultural, sendo que na maior parte dos casos possui apenas a expectativa de aproveitamento de caráter espiritual ou estético (GUERRA, 1999). Além do conhecimento sobre a audiência, para desenhar uma atividade interpretativa é necessário também ter em conta "a proposta de atividades, a eleição dos recursos que nos proporciona o lugar e, a capacidade do guiaintérprete ou dos meios interpretativos utilizados" (DAWSON, 1999, p. 4). É precisamente esse conhecimento das técnicas interpretativas, aliado ao entendimento da audiência e atrativo, que gerará a "oportunidade interpretativa" (NATIONAL PARK SERVICE, 2007).

Embora seja uma ferramenta com muitos âmbitos de aplicação, a IP tem um papel determinante na gestão das áreas protegidas, talvez pelo seu nascimento estar vinculado à criação dos Parques Nacionais nos EUA, favorecendo o desenvolvimento de atividades de uso público e turismo em consonância com os objetivos da conservação. Além disso, colabora com a promoção e democratização do patrimônio junto às comunidades e representa um importante instrumento de desenvolvimento local.

Mediante as diferentes técnicas de apresentação da mensagem, a interpretação facilita informação diversa e atrativa para que as pessoas deixem de ser simples receptoras e se tornem atores num processo de fazer própria a área protegida visitada. Nesse encontro, os intérpretes baseando-se nos atrativos interpretados são a ponte capaz de vincular os interesses e experiências dos visitantes com a alma do lugar. O objetivo é que a informação oferecida chegue à mente, mas também ao coração, produzindo conexões entre os visitantes e o espaço, como destaca Armas (2002, p. 265):

\footnotetext{
A interpretação se baseia na indução no visitante de novos significados de alto valor para ele, por meio do mecanismo da compreensão por revelação direta de acontecimentos ou fenômenos originais que lhe são apresentados. Tem caráter imediato e vai dirigido às emoções dos sujeitos.
}

Uma boa interpretação do patrimônio transforma o público em motivado e receptivo para entender por que e como conservar as áreas protegidas. Para Brochu e Merriman (2002, p. 3), "não há nada mais poderoso que a assimilação voluntária, porque um público que entende ajuda a manter a todos envolvidos no uso precavido dos 
recursos". Morales (2001) acredita que a incorporação da interpretação no planejamento turístico de áreas protegidas não só ajuda a reduzir os impactos negativos que os turistas podem provocar, mas também auxilia na justificativa da existência de tais áreas, divulga os valores do meio e inclusive fomenta o apoio cidadão a diversas tarefas empreendidas pelos órgãos encarregados da conservação.

Mediante a soma de informações relevantes e da técnica adequada, a finalidade é que os visitantes estabeleçam suas próprias conexões entre o que sabem, suas vivências e a área que visitam, compreendendo as consequências de suas ações e adotando um comprometimento que resulte na conservação do lugar.

Neste trabalho são inicialmente apresentados os princípios gerais da interpretação do patrimônio e a relevância da mensagem interpretativa. Posteriormente, descrevem-se os meios e técnicas interpretativas mais frequentes para colocar o patrimônio em contato com os visitantes. Na sequência, mostram-se as vantagens da IP como instrumento de gestão turística em áreas protegidas e a necessidade da participação local no planejamento interpretativo. No fim, reforça-se a ideia da interpretação do patrimônio como estratégia de comunicação que visa a conservação dos atrativos naturais e culturais, assim como o fomento do turismo sustentável em áreas protegidas que abrigam a atividade turística.

\section{A IMPORTÂNCIA DA MENSAGEM INTERPRETATIVA}

$\mathrm{Na}$ tentativa de apresentar os fundamentos teóricos e metodológicos da disciplina, Tilden (2006, p. 36) resume em seis princípios a metodologia para fazer uma boa interpretação:

(i) se não relaciona o mostrado ou descrito com algo que esteja na personalidade ou experiência do visitante, será estéril; (ii) a informação não é por si só interpretação; (iii) é uma arte que pode ser ensinada; (iv) seu objetivo principal não é a instrução, mas sim a provocação; (v) deve apresentar o todo em lugar das partes; (vi) aquela dirigida a um público infantil, não dever ser uma diluição da oferecida aos adultos. 
Murta e Albano (2002, p. 18) acrescentam que "as parcerias com a comunidade; a adoção de abordagens abrangentes; a diversidade e pluralidade culturais e; o atendimento ao cliente" são elementos a ter em conta para o seu desenvolvimento.

A IP busca a modificação de comportamentos e mobilização por meio do entendimento e da apreciação. Procura que o visitante deixe de ser um estranho e naquele momento da visita sinta-se parte do lugar, captando a singularidade do atrativo (MURTA; ALBANO, 2002). Em relação a isso, Ham (1992) lembra que uma atitude favorável não sempre se traduz em comportamentos favoráveis, pois há outros fatores implicados, concretamente as crenças. Por isso, para influenciar os visitantes de maneira que estes se comportem de uma forma responsável e colaborem ativamente na proteção dos valores das áreas protegidas, será imprescindível influenciar nas suas convicções sobre comportamentos específicos.

Nesse sentido, as mensagens oferecidas poderão influir nas crenças dos visitantes e no seu posterior comportamento, sempre que sejam pertinentes, amenas, temáticas e organizadas (HAM, 1992). Serão pertinentes quando tenham significado para quem as recebe, ou seja, quando se relacionem com as experiências e conhecimentos dos visitantes; por isso é importante colocar as pessoas "no lugar de" e transmitir informações que tenham a ver com o seu "ego" e vivências pessoais. Poderão resultar mais amenas se as mensagens utilizam verbos ativos, apresentando a relação direta entre causa e efeito e, utilizando analogias, metáforas visuais ou ilustrações que permitam mostrar mais claramente relações ou processos complexos. A Figura 1 mostra um exemplo de placa interpretativa que utiliza analogias (tamanho corporal da criança e do animal) e comparações de processos complexos (funcionamento da escavadora e estratégia de fuga do animal) para facilitar a compreensão da mensagem. 


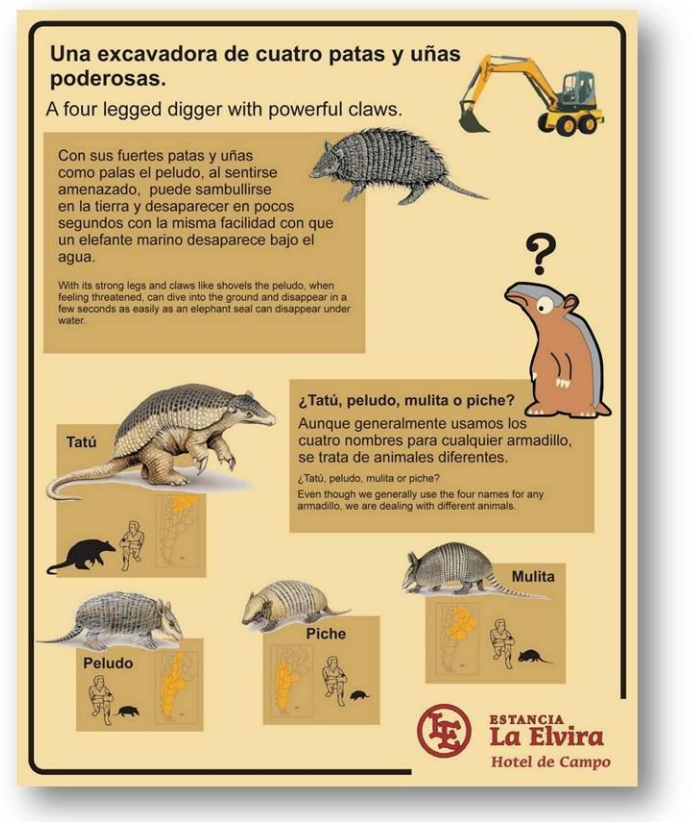

FIGURA 1 - EXEMPLO DE PLACA INTERPRETATIVA DA ÁREA NATURAL PROTEGIDA PENÍNSULA VALDÉS (PATAGÔNIA ARGENTINA); FONTE: SERANTES PAZOS, A. ARQUIVO DA AUTORA.

As mensagens serão temáticas se oferecem a informação em forma de relato ou historia, mediante uma frase simples (com sujeito, verbo e predicado), com enunciados curtos e fáceis de compreender; os temas são as ideias que se transmitem com uma intencionalidade ou objetivo predeterminado. Finalmente, estarão organizadas, se as mensagens se mostram estruturadas em categorias. Miller (1956) assegurava que as pessoas podem lembrar um número limitado de ideias $(7 \pm 2)$ num processo de comunicação devido a que muitas ideias podem converter o processo de comunicação em ineficaz. Estudos mais recentes (BADDELEY, 1996; COWAN, 2001; WEINSCHENK, 2011) mostraram que o número "mágico" de uma mensagem interpretativa consiste em apresentar 4 ideias relacionadas com o tema principal.

Segundo Brochu e Merriman (2002, p. 4) "a interpretação do patrimônio é ao mesmo tempo arte e ciência". Fala-se de IP como "arte" por que na hora de estabelecer a ponte entre os atrativos e a audiência, possibilitando um melhor entendimento do lugar, fatos ou processo, se utilizam estratégias e recursos de maneira criativa que podem ser considerados como artísticos, sem com isso perder o valor científico.

Para Veverka (1994) os objetivos de um processo interpretativo correspondem a três categorias: objetivos educativos, aquilo que os visitantes deveriam conhecer como resultado da interpretação; objetivos emocionais, relacionados com o que deveriam 
sentir e; objetivos comportamentais, vinculados com o que deveriam fazer. Assim, uma vez que se sabe o que se quer contar, é preciso considerar alguns elementos básicos que ajudem no entendimento da mensagem, como por exemplo, envolver os cinco sentidos e colocar a disposição alguns objetos como lembrança.

Os melhores temas interpretativos são os que conectam coisas tangíveis com ideias intangíveis (HAM, 1992; MORALES, 2001; MORALES; GUERRA; SERANTES, 2009). As ideias intangíveis facilitam conexões, superando os simples fatos, misturando ideias com significados. São as ideias intangíveis as que provavelmente "atraem a todas as pessoas, independentemente de seus filtros e experiências individuais" (BROCHU; MERRIMAN, 2002, p. 47). Também é recomendável utilizar conceitos universais, ou seja, aqueles compartilhados por todos os seres humanos, como amor, fraternidade, morte, família, maternidade, amizade, liberdade etc.

Por fim, cabe enfatizar que uma atividade é interpretativa quando os visitantes participam dela de forma voluntária durante o seu tempo livre e, portanto, a interpretação do patrimônio não tenta instruir o público, senão provocar o seu interesse e sensibilidade. A interpretação se faz na mente do público, “em seu próprio entendimento, produção de pensamentos e significados durante e depois do passo por uma atividade ou serviço interpretativo" (MORALES; GUERRA; SERANTES, 2009, p. 6).

\section{MEIOS E TÉCNICAS INTERPRETATIVAS}

Embora existam diferentes meios interpretativos, a seguir se apresentam as características dos três mais frequentes.

- Trilhas ou itinerários.

É o meio interpretativo mais utilizado, permitindo conhecer os valores do lugar de uma forma amena, relevante, participativa e ordenada, ao mesmo tempo em que possibilita a interação das pessoas com o espaço. Este recurso favorece que os visitantes 
se convertam em atores da sua própria experiência e se envolvam diretamente com a área protegida. Tilden (2006, p. 119) defende que:

[...] é fundamental que no âmbito da interpretação a participação seja física. Se tentar incluir todo o que seja completa ou predominantemente mental, a palavra começa a perder seu significado. Não só deve implicar um ato físico, também deve tratar-se de algo que o próprio participante considere novo, especial e importante para si mesmo.

Trilhas bem planejadas possibilitam proteger os atrativos e ao mesmo tempo cuidar dos visitantes, regulando o acesso e o número de visitantes a cada lugar. Ao planejá-las, é importante mostrar aos visitantes lugares singulares e características destacadas do espaço natural, mas evitar zonas de perigo e/ou sensíveis à ação e presença humana.

As trilhas interpretativas têm que ser sempre temáticas. Serrel (1996) define o tema como uma boa ideia que inspira o desenho interpretativo. As paradas nas trilhas se configuram em torno a um tópico geral (por exemplo, "a floresta", "a desertificação" ou "a conservação") que se concentra em uma frase-tema (por exemplo, "a floresta nativa nos alimenta", "algumas ações humanas estão convertendo este lugar num deserto" ou “a conservação desta área protegida aumenta a qualidade de vida da comunidade local"). Em cada parada se aborda o tema desde distintas perspectivas ou se elaboram subtemas para reforçar e aprofundar a ideia principal do percorrido. A trilha tem que estar planejada, deve integrar um relato lógico e ordenado, para que as pessoas possam entender a importância do lugar. Para isso, desenha-se o itinerário em paradas temáticas. Em cada parada há uma introdução, um corpo e uma conclusão, sendo recomendável realizar uma transição no final de cada parada que atue como ponte de relato entre as paradas (HAM, 1992).

Segundo Serantes (2010, p. 179), atendendo aos objetivos procurados, as trilhas podem ser:

- de relato ou de lugar: o que se pretende é dar a conhecer a importância do lugar ou de alguma peculiaridade do mesmo, por meio de uma história ou das características de distintos elementos (flora, geologia, paisagem, cultura, dentre outros). Nas paradas são abordados distintos aspectos que ajudam a recrear o tema da trilha, e a ordem das paradas pode variar sem que com isso mude o objetivo da trilha; 
- didáticas: pensadas e desenhadas sequencialmente para que os visitantes conheçam determinados aspectos da área protegida (por exemplo, um programa de recuperação de fauna silvestre, o combate a uma planta invasora ou o etnoconhecimento local) e, portanto, contam com paradas sequenciadas para conseguir uma aprendizagem significativa. Neste caso, a ordem para abordar os conteúdos é fundamental;

- turísticas ou recreativas: elaboradas para que os visitantes tenham simplesmente uma experiência gratificante no lugar. $O$ desenho está baseado na surpresa, na singularidade de algumas características e na provocação da participação (por exemplo, a importância dos morcegos no controle de pragas ou o conhecimento das estratégias de sobrevivência das plantas). Os elementos e as paradas são desculpas para interagir com o meio. A ordem dos conteúdos nas paradas não é um fator importante;

- cognitivas: incluem as trilhas que se desenham para compreender um processo natural ou socioambiental (a formação de uma lagoa, o êxodo rural, etc.), apresentando os elementos de forma intencional. A ordem dos conteúdos mostrados nestas trilhas descreve sequencialmente o processo de formação ou evolução dos elementos apresentados.

Recomenda-se evitar as trilhas lineares que começam em um ponto e acabam em outro diferente, assim como aquelas que vão e voltam pelo mesmo caminho (HAM, 1992; MORALES, 2001; FRATTO, 2004). Essas últimas são pouco aconselháveis quando o percorrido é muito frequentado já que os visitantes têm a sensação de saturação ao se cruzar constantemente com outras pessoas que interferem negativamente na experiência. Sempre que possível, e para diminuir a capacidade de suporte do local, o melhor seria desenhar trilhas circulares de uma direção, com o mesmo ponto de partida e chegada e onde os visitantes não se cruzem uns com outros.

Por outro lado, as trilhas interpretativas podem se dividir em guiadas ou autoguiadas, tendo em conta se o grupo de visitantes dispõe do apoio de um guiaintérprete (monitor) ou se a visita se realiza de forma autônoma. Nas trilhas guiadas o guia adquire um protagonismo especial por que é quem conhece o lugar e a trilha préestabelecida; um bom guia-intérprete fica em um segundo plano, dando-lhe protagonismo ao lugar e aos visitantes; sua função, ademais de garantir a segurança dos visitantes, é facilitar informação relevante de forma atrativa. Já as trilhas autoguiadas 
precisam de outros insumos para se realizar de forma autônoma e segura (como cartilhas, sinais e setas, marcas, placas explicativas e audioguias).

O número de paradas nas trilhas guiadas depende de fatores como o tempo disponível, a dificuldade do percorrido, as características do grupo e a complexidade do tema. Um número de referencia é 10, contando a parada de encontro do grupo, a primeira, a última e mais 7 paradas onde se desenvolverão os subtemas ou conteúdos (WIDNER; WILKINSON, 2006). Já nas autoguiadas, devem evitar-se distâncias maiores de 2 quilômetros, não realizando mais de 15 paradas e concentrando-as mais no começo, pois é quando as pessoas estarão mais motivadas e menos cansadas (MORALES, 2001).

- Placas, sinais, painéis e letreiros interpretativos.

Proporcionam, de forma atrativa e sem interferir nos cenários naturais, informação referida a alguma característica essencial do recurso turístico visitado, relevante para o visitante pelo seu significado. Este meio resulta interessante em lugares muito frequentados, nos que não há serviço personalizado, ou bem onde o impacto dos visitantes é baixo. Podem empregar-se tanto no exterior (de apoio às trilhas autoguiadas) como no interior (em exposições e centros de visitantes).

O processo comunicativo se baseia na mensagem escrita, que deve ser reforçada por ilustrações, fotografias, planos ou esquemas. O texto das placas estrutura-se em 6 níveis (Figura 2) que deveriam diferenciar-se visualmente pelo tamanho da letra, podendo enfatizar a diferença utilizando cores distintas e jogando com a distribuição do texto (MORALES, 2001, p. 228; SERANTES, 2010, p. 184):

- nível I ou título-tema, apresenta o tema ou um elemento do tema, por meio de uma frase com sujeito, verbo e predicado;

- nível II ou parágrafo de atração, deve aprofundar, com pouco detalhe, em algum aspecto do título despertando interesse. Convém destacar que muitas pessoas apenas irão ler esses dois primeiros níveis pelo que é preciso que entre ambos se aporte a informação relevante;

- nível III ou parágrafo principal, que aprofunda no tema, evitando superar as 50 palavras; 
- nível IV ou parágrafo de encerramento, nele se convida a desenvolver uma ação, se apresenta uma conclusão ou se informa de algum aspecto relevante para a área protegida;

- nível V ou parágrafos auxiliares, usados para facilitar outra informação mais exaustiva de algum aspecto interessante;

- nível VI ou créditos, destinado a incluir o nome da trilha, as logomarcas das instituições e a imagem corporativa da trilha.

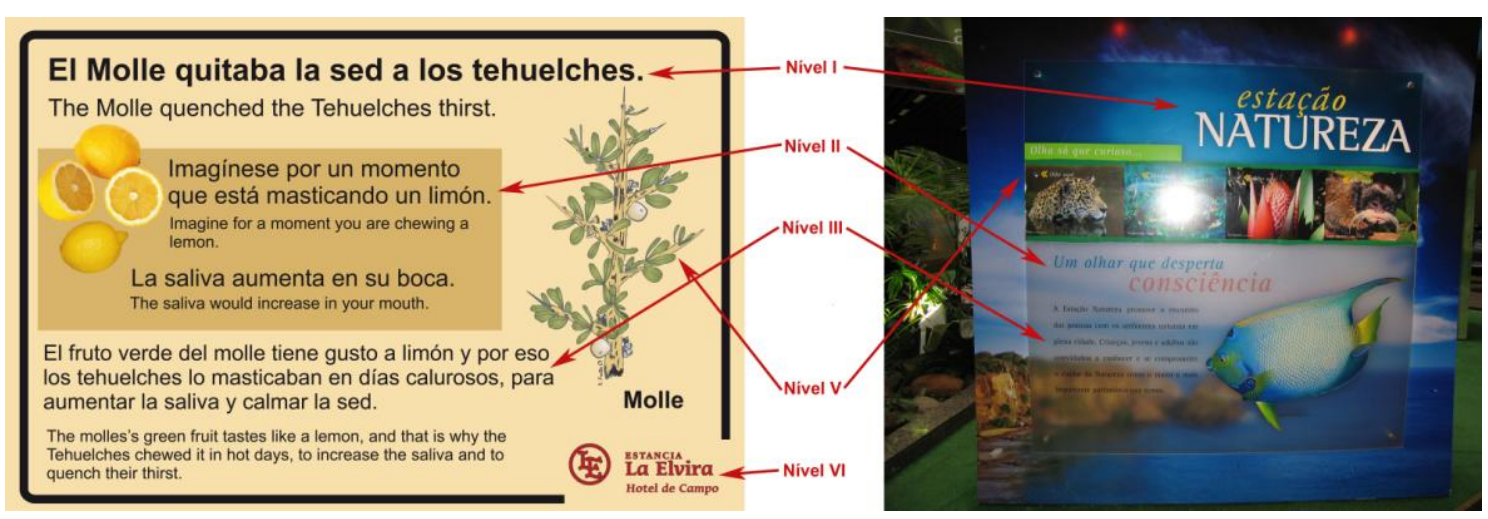

FIGURA 2 - EXEMPLOS DE ESTRUTURA DO TEXTO EM PLACAS INTERPRETATIVAS PARA EXTERIOR E INTERIOR. A) ÁREA NATURAL PROTEGIDA PENÍNSULA VALDÉS (PATAGÔNIA ARGENTINA); B) EXPOSIÇÃO "ESTAÇÕES NATUREZA" DA FUNDAÇ̃̃O O BOTICÁRIO (CURITIBA, BRASIL); FONTE: SERANTES PAZOS, A. ARQUIVO DA AUTORA, ELABORAÇÃO: BURGOS, A.; SERANTES, A., 2013.

No momento da composição da placa, o alinhamento do texto a esquerda é a melhor opção para a sua leitura. Os títulos ou manchetes poderão estar centrados porque isso oferece equilíbrio e elegância. Para destacar diferentes subtemas se utilizam parágrafos, não sendo recomendável o uso de recuo na primeira linha. $\mathrm{O}$ uso de parágrafos deixa o texto mais legível. Nos parágrafos auxiliares se recomenda apresentar o texto em "caixas" e compacto, com um parágrafo para cada texto auxiliar (HAM, 1992).

O tamanho da letra deverá ser definido em função da distância da placa e do nível de informação, já que as hierarquias de tamanho ajudam a identificar a importância da informação. Ham (1992) recomenda um tamanho para os titulares e parágrafo de atenção dentre 96 e 72 pontos, e para os textos auxiliares de 18 a 24.

Também é importante considerar as fontes de letra. Todas as fontes transmitem mensagens, mas é interessante escolher o tipo em função do conteúdo e da sua 
colocação na placa (desenho). Jardí (2007) e Moscardo; Balantyne; Hugues (2007) oferecem dicas úteis a este respeito, recomendando, entre outras coisas, o uso de não mais de 1 ou 2 fontes de letras para não distorcer a mensagem; não mais de 60 caracteres (incluídos os espaços), umas 10 palavras por linha de texto e; prestar atenção as cores, já que embora elas possam acrescentar significado aos textos (por exemplo, cores quentes como vermelho, laranja e amarelo, atraem a atenção e podem indicar perigo), seu uso indiscriminado e anárquico pode dificultar, ou inclusive dissuadir, a leitura.

Para facilitar a leitura recomendam-se os fundos escuros e letras claras para placas em lugares escuros, e fundos claros e letras escuras para interiores e zonas de penumbra. Os materiais de fabricação mais apropriados são aqueles resistentes, mas coerentes com o entorno; e o melhor formato é o retangular, com placas horizontais destinadas ao exterior, e verticais a interiores ou para a exposição de normas aos visitantes.

Finalmente, Veverka (1994) aponta que as pessoas lembram em média $10 \%$ do que escutam, $50 \%$ do que veem e $90 \%$ do que fazem. Por isso, o desenho de placas interpretativas ajuda a compreensão da mensagem, por meio de ações ou elementos tridimensionais, interativos ou que se possam manipular. Nesse sentido, a formulação de perguntas pode ser também uma boa alternativa de interagir com os visitantes (MOSCARDO; BALANTYNE; HUGUES, 2007).

- Centros de visitantes.

Por vezes também conhecidos como centros de interpretação, são os locais que revelam in situ aos visitantes o significado das áreas protegidas. Normalmente, para ajudar nessa tarefa e apresentar a informação, dispõem de numerosos recursos, tais como placas, maquetas, objetos reais ou reproduções, manequins, audiovisuais, exibições e hologramas. Ademais, constituem um serviço de referência para os visitantes que querem receber informação dos valores do lugar, dos serviços disponíveis e das possibilidades de desenvolver atividades (SERANTES, 2011, p. 105).

A localização dos centros é estratégica, aconselhando-se que fiquem em locais de fácil acesso, de preferência fora da área protegida, mas na entrada das mesmas, em 
lugares pouco vulneráveis que suportem a pressão das visitas e que contem com alguns elementos destacáveis do espaço natural. O objetivo é que sirvam de transição entre os visitantes e o novo espaço a ser descoberto, preparando-os psicologicamente de forma favorável (MACKINNON, 1985; MORALES, 2001; LEWIS, 2005). Sureda (2008, p. 87) os considera o ponto de passagem da fronteira à entrada no território e "um meio idôneo para as pessoas que não tem tempo ou oportunidade de realizar uma visita mais aprofundada".

Para estimular o conhecimento do lugar, a informação facilitada deve ser sugestiva e pertinente, promovendo comportamentos que assegurem a conservação dos atrativos apresentados e informando as medidas que estão sendo adotadas na área protegida, de maneira a ajudar os visitantes a terem comportamentos respeitosos.

Os centros de visitantes combinam três elementos: o espaço físico, os objetos e o roteiro. O espaço físico é o suporte que limita e ao mesmo tempo oferece possibilidades. Contudo, é imprescindível que os centros de visitantes contem histórias, que tenham "conteúdo", por meio de um fio condutor que se apresente de forma ordenada para darlhe sentido aos temas. Ao contrário dos museus, recomenda-se realizar o desenho forçando os visitantes a seguirem um caminho de visita, para que assim possam construir uma mensagem clara (SERANTES, 2010). No momento de estruturar os conteúdos, é importante que nem todos os elementos fiquem visíveis ao entrar no centro, senão que existam pequenos locais e cantos que gerem curiosidade e surpresa.

Atualmente a tendência é que os centros de visitantes sejam espaços multifuncionais, com uso frequente das novas tecnologias. Embora as tecnologias possam cumprir um papel importante, são muitos os autores (HAM, 1992; MORALES, 2001; BROCHU; MERRIMAN, 2002) que recomendam priorizar a interpretação personalizada como complemento ao serviço, devido a melhor obtenção de resultados por meio das visitas guiadas.

Um dos principias problemas relacionados com esses equipamentos ocorre quando os visitantes cobrem sua expectativa de conhecer uma área protegida unicamente com uma visita ao centro de visitantes. Para evitar isto, recomenda-se desenhar trilhas de curta duração nas imediações dos centros que permitam uma experiência e vivência in situ de alguns dos valores do lugar. Contudo, o maior problema na atualidade é sem dúvida a construção de iniciativas deste tipo que se 
desenvolvem sem nenhum planejamento, não respondendo a necessidades reais, tal e como salienta Martín (2008, p. 5) quando define este meio interpretativo como:

[...] um equipamento de uso público que foi desenhado em função de vários fatores. Em primeiro lugar e como condição imprescindível, como uma necessidade derivada de um planejamento de uso público e em resposta a um plano de serviços interpretativos, e não como um produto determinado por uma vontade a priori.

No quadro 1, são apresentadas, de forma resumida, as principais vantagens e desvantagens dos três meios interpretativos descritos.

\section{QUADRO 1 - PRINCIPAIS VANTAGENS E DESVANTAGENS DOS MEIOS INTERPRETATIVOS MAIS FREQUENTES EM ÁREAS PROTEGIDAS.}

\begin{tabular}{|c|c|}
\hline \multicolumn{2}{|c|}{ TRILHAS } \\
\hline Vantagens & Desvantagens \\
\hline $\begin{array}{l}\text { Facilitam o contato personalizado com o objeto } \\
\text { patrimonial. } \\
\text { Regulam o acesso e ajudam na gestão de } \\
\text { lugares muito demandados. } \\
\text { Guiadas, podem se adaptar a interesses, } \\
\text { características e capacidades do grupo. } \\
\text { Autoguiadas oferecem maior flexibilidade e } \\
\text { liberdade do usuário. }\end{array}$ & $\begin{array}{l}\text { Guiadas: mais caras, se houver má planejamento } \\
\text { de uso; requerem grupos reduzidos de pessoas; } \\
\text { dependem de horários pré-estabelecidos e de } \\
\text { monitores/guias disponíveis. } \\
\text { Autoguiadas: mais impessoais; expostas o } \\
\text { vandalismo; em alguns casos podem causar } \\
\text { bastante impacto visual. }\end{array}$ \\
\hline \multicolumn{2}{|c|}{ PLACAS INTERPRETATIVAS } \\
\hline Vantagens & Desvantagens \\
\hline $\begin{array}{l}\text { Interessantes em lugares muito frequentados, } \\
\text { sem serviço personalizado e baixo impacto. } \\
\text { Servem de apoio a trilhas autoguiadas ou para } \\
\text { exposições e centros de visitantes. } \\
\text { Podem ser usadas por vários visitantes e em } \\
\text { diferentes idiomas ao mesmo tempo. } \\
\text { Mais baratas (desembolso inicial e de } \\
\text { manutenção). }\end{array}$ & $\begin{array}{l}\text { Difíceis de controlar e atualizar; expostas ao } \\
\text { vandalismo. } \\
\text { Não respondem dúvidas. } \\
\text { Requerem maior esforço e vontade por parte dos } \\
\text { visitantes. } \\
\text { Exigem bons conhecimentos de desenho } \\
\text { interpretativo. Podem causar impacto visual. }\end{array}$ \\
\hline \multicolumn{2}{|c|}{ CENTROS DE VISITANTES } \\
\hline Vantagens & Desvantagens \\
\hline $\begin{array}{l}\text { Oferecem boas-vindas, facilitam informação } \\
\text { sobre o uso, orientam as pessoas e apresentam a } \\
\text { instituição responsável. } \\
\text { Reduzem o impacto concentrando as visitas em } \\
\text { pontos controlados e menos vulneráveis. } \\
\text { Ajudam a contextualizar o espaço, criando } \\
\text { conexões com as experiências prévias dos } \\
\text { visitantes os motivando favoravelmente. }\end{array}$ & $\begin{array}{l}\text { Muitas vezes são concebidos como fim em si } \\
\text { mesmo e não como instrumento de conservação. } \\
\text { Requerem instalação em local estratégico e } \\
\text { planejamento prévio. Mal desenhados e } \\
\text { sinalizados, estarão condenados ao fracasso e } \\
\text { podem ser um problema para a gestão do espaço. } \\
\text { São caros e devem prever o custo de manutenção, } \\
\text { funcionamento e o associado à contratação de } \\
\text { pessoal. }\end{array}$ \\
\hline
\end{tabular}

FONTE: ELABORAÇÃO PRÓPRIA.

Por fim, há que destacar a necessidade de favorecer a acessibilidade física e intelectual de todos os tipos de público ao patrimônio natural e cultural, e, portanto, além de optar pelas informações dos meios interpretativos por critérios didáticos, sem 
perda de rigor científico, deveria ser indispensável o uso de complementos adaptados a pessoas com algum tipo de deficiência.

\section{TURISMO E CONSERVAÇÃO DE ÁREAS PROTEGIDAS}

A natureza e seus recursos são atrativos turísticos cada vez mais comuns na sociedade e, consequentemente, as áreas protegidas vêm sendo consideradas como importantes espaços recreativos, se posicionando como destinos turísticos de moda capazes de satisfazer a crescente demanda de visitação existente. Nesse cenário, um dos perigos reais é a banalização desses destinos e bens de uso comum. Não respeitando a capacidade de suporte do ambiente, a atividade turística se apropria do espaço público, podendo transformar os destinos em "produtos étnicos", frutos do modismo de consumo da natureza, mudando os usos do lugar e provocando trocas culturais, assim como distribuição desigual da renda.

Tendo em consideração as fases que, segundo Butler (1980), atravessa um destino turístico (exploração, implicação local, desenvolvimento, consolidação, estancamento e, declive ou rejuvenescimento) é evidente que as práticas turísticas desenvolvidas em áreas protegidas podem terminar superando a capacidade de carga do espaço, repercutindo negativamente sobre os valores naturais e culturais que em si mesmos constituem o atrativo turístico.

Nesse sentido, a interpretação do patrimônio permite fomentar o turismo sustentável, ao tempo que possibilita mitigar ou eliminar os perigos de um turismo de massa. "O principal foco da interpretação é estabelecer uma comunicação efetiva com o visitante, mantendo importantes interfaces com o turismo, a preservação do patrimônio e o desenvolvimento cultural das comunidades locais" (MURTA; ALBANO, 2002, p. $10)$.

A interpretação do patrimônio ajuda a planejar circuitos e recursos para controlar os fluxos de visitantes, respeitando a capacidade de carga dos lugares e evitando a vulnerabilidade sazonal de alguns destinos. Com isso, pode dar respostas aos viajantes mais interessados pelas problemáticas socioambientais que procuram o contato direto com a natureza e o conhecimento de outras culturas. Ademais, se apresenta como 
"mediadora" entre visitantes, comunidade local e gestores, aliviando os conflitos existentes e prevenindo os potenciais, ao salientar de forma relevante os objetivos da conservação e suas vantagens.

A IP é um instrumento que pode favorecer a gestão de áreas protegidas porque permite estabelecer conexões entre os bens ou recursos (naturais e culturais), as experiências vividas pela comunidade local e as expectativas dos visitantes, sendo que tais pontes intelectuais e emocionais são imprescindíveis para contar com o apoio da sociedade no cuidado e conservação de ecossistemas, espécies e serviços ambientais. Segundo Morales e Guerra (1996), o conceito de instrumento de gestão se aplica à interpretação do patrimônio enquanto que esta disciplina tem a possibilidade de promover um comportamento coerente com o lugar, conscientizando sobre a importância de conservá-lo, estimulando e persuadindo, ao mesmo tempo em que facilita o bom uso do espaço por meio de desenhos adequados e programas bem concebidos, que concentram ou dispersam os visitantes em função dos distintos graus de sensibilidade dos locais.

Nesse sentido, a IP oferece informação e serviços aos visitantes. Ajuda também no planejamento dos usos do espaço, colocando à disposição os serviços interpretativos nos locais que os gestores consideram menos vulneráveis, sem minguar na satisfação da experiência, e respondendo as expectativas dos visitantes. Junto com a informação e a educação ambiental, a interpretação do patrimônio é um excelente instrumento para o planejamento do uso público, já que os serviços interpretativos se ajustam as possibilidades de uso do espaço, selecionando lugares e conteúdos. Além disso, esse instrumento contribui para divulgar tanto os atrativos turísticos quanto as medidas de conservação que estão sendo implementadas.

\section{PLANEJAMENTO INTERPRETATIVO E PARTICIPAÇÃO LOCAL}

Para contribuir com a conservação das áreas protegidas é preciso planejar o uso de seus atrativos. O planejamento interpretativo constitui um instrumento eficaz para mostrar os espaços naturais como destino, sem impactar nos seus valores, ajudando a consolidar boas práticas turísticas em entornos sensíveis ou vulneráveis. Uma boa 
interpretação consegue que "a audiência regresse, que compartilhe seu entusiasmo sobre a experiência com amigos e que permaneça por mais um tempo a próxima vez que visite o lugar" (BROCHU; MERRIMAN, 2002, p. 19).

Muitas áreas protegidas são também territórios habitados, com presença de comunidades dentro dessas áreas ou no seu entorno e que dependem, em grande medida, dos recursos da zona. A interpretação permite despertar novas vocações, assim como criar novos centros de interesse e serviços que podem converter-se em oportunidades de trabalho e renda e, assim, incidir positivamente no desenvolvimento local. Uma boa interpretação pode converter em "produto" as singularidades de uma área protegida, ampliando a oferta de serviços locais compatíveis com a conservação, de forma mais atrativa e rentável.

Ao mesmo tempo a IP facilita um olhar global entre cultura e território, sem instrumentalizar a identidade local, serve para potencializar a conexão e o sentido de pertencimento por meio do conhecimento e valorização do próprio, ajudando a que a comunidade compreenda (e sinta) os benefícios da conservação. Nesse sentido, também pode atuar como mediadora das comunidades locais para resgatar sua história e sua cultura por meio de um trabalho de educação patrimonial (FARIAS, 2006).

O planejamento interpretativo requer a coordenação e cooperação de diferentes atores implicados e, portanto, a necessidade de uma abordagem multidisciplinar donde, além de profissionais do campo da interpretação, trabalhem também técnicos de diferentes áreas (designers, arquitetos, historiadores, biólogos, antropólogos, sociólogos, educadores, dentre outros), representantes da administração pública, trabalhadores da área protegida e membros de associações. Porém, as comunidades locais possuem um papel fundamental, sendo necessário não apenas que atuem como "espectadores" da atividade interpretativa planejada por "outros", senão que sejam atores principais, com um nível de participação que supere a da simples informação e consulta para situar-se na esfera decisória da gestão, atuando em todas as fases do planejamento.

Deste modo, a incorporação das comunidades locais no planejamento interpretativo e, portanto, a obtenção de um maior controle sobre os recursos e seu futuro está intimamente relacionada com a sustentabilidade. Assim, Irving (2002), ao analisar a questão da participação como garantia de sustentabilidade argumenta que a 
minimização dos impactos negativos das práticas turísticas passa por novos modelos de implementação de projetos, centrados em parcerias onde se valorize a participação das comunidades, baseados no saber compartilhado, nas relações horizontais e na noção de empoderamento.

O papel da comunidade receptora neste processo é fundamental porque o turismo, como prática econômica, precisa encontrar formas respeitosas de se inserir no cotidiano das comunidades, por meio de investimentos adequados à vocação do lugar que possibilitem à população participar e usufruir os resultados obtidos (MURTA; ALBANO, 2002).

Por outro lado, há que ter em conta que a prática interpretativa exige um bom conhecimento do entorno e da história do lugar. É ela que dá à destinação a sua personalidade, seu caráter único, diferenciando o destino turístico e o excluindo de lugares comuns. Goodey (2002, p. 47), refletindo sobre a interpretação como processo que se baseia na comunidade afirma:

\footnotetext{
Quem tem o conhecimento mais enraizado e rico sobre um lugar são aquelas pessoas que lá cresceram, ou aquelas que lá se estabeleceram [...] Em contrapartida, costuma existir também sobre o lugar um conhecimento especializado [...] mas este geralmente peca pela falta de vivência cotidiana, a qual assegura de fato que qualquer interpretação se faça viva, não sendo apenas algo que repouse friamente sobre uma página ou um painel.
}

Por isso, a integração das comunidades no planejamento interpretativo resulta essencial, já que como anfitriões, são as que melhor podem transmitir o "espírito" desse destino turístico, por meio dos valores e recursos próprios do território, ajudando assim a entender a "alma" que esse lugar possui. Durante esse processo de planejamento local, a comunidade poderá ter uma consciência do seu patrimônio e decidir sobre aquilo que deseja compartilhar e o que deseja só guardar para si, sendo que aquilo que a comunidade valoriza para si própria, o que ela deseja preservar, é possivelmente o que ela vai querer compartilhar com os outros (GOODEY, 2002).

Assim, a interpretação do patrimônio como instrumento participativo de gestão de áreas protegidas deveria ser um processo que levasse as comunidades locais a reforçar laços sociais e sua identidade, ampliando a relação entre visitantes, comunidade e patrimônio, gerando alternativas comunicacionais e oportunidades turísticas que 
garantam a integração social (MARAGLIANO, 2010). Em relação a isso, Murta e Albano (2002, p. 11) destacam:

\begin{abstract}
A prática interpretativa deve promover a discussão entre os vários segmentos sociais sobre aquilo que torna seu lugar especial e diferente. Deve também levar os moradores a (re)descobrir novas formas de olhar e apreciar seu lugar, de forma a desenvolver entre eles atitudes preservacionistas. Finalmente deve despertar novas vocações e possibilitar oportunidades de trabalho e renda ligados ao turismo.
\end{abstract}

Finalmente, convém salientar que o necessário desenvolvimento de práticas interpretativas em áreas protegidas, além de realizar-se por meio de um planejamento que envolva as comunidades em todos os seus aspectos, não deveria se basear exclusivamente na importação de modelos norte-americanos e europeus, senão na criação de modelos próprios e diferenciados, aproveitando a bagagem de outras experiências vindas de latitudes onde sua prática sistemática foi estabelecida, mas se adequando a realidades específicas do território.

\title{
6 CONSIDERAÇÕES FINAIS
}

A interpretação do patrimônio é uma ferramenta que pode contribuir tanto com o planejamento do uso e a conservação dos valores de uma área protegida, quanto com o desenvolvimento local e a experiência dos visitantes. Serve como instrumento para introduzir critérios de qualidade ambiental e sustentabilidade no planejamento turístico, e se apresenta como "mediadora" entre visitantes, comunidade local e gestores, aliviando os possíveis conflitos ao salientar de forma relevante os objetivos da conservação e suas vantagens.

O desenho de trilhas guiadas e autoguiadas, com apoio de placas interpretativas, assim como os centros de visitantes, são algumas das estratégias usadas pela interpretação do patrimônio para ajudar a conciliar a conservação das áreas protegidas, o desenvolvimento local e o turismo.

O planejamento e desenho de recursos interpretativos permite criar uma rede de atrativos e serviços que facilitam a mobilidade e distribuição dos visitantes, possibilitando controlar o seu impacto ambiental e sociocultural. Ademais, favorece a 
valorização da cultura e identidade local, o surgimento de novos centros de interesse e as oportunidades de emprego e renda para as comunidades.

$\mathrm{Na}$ relação que se estabelece entre os visitantes e a área protegida, as comunidades que recebem o turista oferecem a personalidade local e são as que melhor podem transmitir o "espírito" do lugar, os valores locais, materiais e espirituais, embora provavelmente precisem ajuda sobre como o fazer. Surge então a necessidade de implementar processos de planejamento interpretativo com base local no que os intérpretes trabalhem junto com as comunidades com o objetivo de ajudá-las a compreender e trabalhar sua própria imagem do lugar, e assim, atrair visitantes que não comprometam a integridade dos espaços visitados enquanto aportam benefícios socioeconômicos para as comunidades receptoras.

\section{REFERÊNCIAS}

AIP. Editorial. Boletín de Interpretación, España, n. 1, p. 1, jun. 1999. Disponível em: <http://www.interpretaciondelpatrimonio.com/boletin/index.php/boletin/issue/view/6>. Acesso em: 02/04/2013.

ARMAS, A. Uso Público y Educación Ambiental en Espacios Naturales Protegidos. In: CENTELlAS, A. (Org.) Elementos para la interpretación del Parque Nacional de Timanfaya. Madrid: Ministerio de Medio Ambiente, 2002, p. 259-276.

BADDELEY, A. D. The concept of working memory. In: GATHERCOLE, S. (Ed.) Models of short-term memory. Hove: Lawrence Erlbaum Associates - Taylor and Francis, 1996, p. 1-28.

BROCHU, L; MERRIMAN, T. Personal interpretation. Singapore: National Association of Interpretation, 2002.

BUTLER, R. W. The concept of a tourist area cycle of evolution: implications for management of resources. Canadian Geographer, v. 4, n. 1, p. 5-12, 1980.

COWAN, N. The magical number 4 in short-term memory: A reconsideration of mental storage capacity. Behavioral and Brain Sciences, v. 24, p. 87-114, 2001.

DAWSON, L. Como interpretar recursos naturales e históricos. Costa Rica: Fondo Mundial para la Naturaleza-WWF, 1999. 
FARIAS, G. La interpretación del patrimonio en Brasil. Boletín de Interpretación, España, n. 15, p. 11-13, ago. 2006. Disponível em:

$<$ http://www.interpretaciondelpatrimonio.com/boletin/index.php/boletin/article/view/18 6>. Acesso em: 02/04/2013.

FRATTO, V. Detrás de la escena de un sendero interpretativo. Boletín de Interpretación, España, n. 11, p. 11-13, ago. 2004. Disponível em:

$<$ http://www.interpretaciondelpatrimonio.com/boletin/index.php/boletin/article/view/23 1>. Acesso em: 02/04/2013.

GOODEY, B. Interpretação e comunidade local. In: MURTA, S.; ALBANO, C. (Org.) Interpretar o patrimônio: um exercício do olhar. Belo Horizonte: UFMG, 2002, p. 4758.

GUERRA, F. Elementos para el debate. Boletín de Interpretación, España, n. 1, p. 34, jun. 1999. Disponível em:

$<$ http://www.interpretaciondelpatrimonio.com/boletin/index.php/boletin/article/view/21

$>$. Acesso em: 02/04/2013.

HAM, S. Environmental Interpretation: A Practical Guide for People with Big Ideas and Small Budgest. Colorado: North American Press, 1992.

IRVING, M. A. Participação: questão central na sustentabilidade de projetos de desenvolvimento. In: IRVING, M. A.; AZEVEDO, J. (Org.) Turismo, o desafio da sustentabilidade. São Paulo: Futura, 2002, p. 35-45.

JARDÍ, E. Veintidós consejos sobre tipografía. Barcelona: Actar D, 2007.

LEWIS, W. Interpreting for Park Visitors. USA: Eastern National, 2005.

MACKINNON, L. The orientation role of visitor centers in national and historic parks (MMSt research paper) - University of Toronto, 1985.

MARAGLIANO, G. Interpretación del Patrimonio: una forma de comunicación que revela los significados del legado. Boletín de Interpretación, España, n. 22, p. 17-20, mar. 2010. Disponível em:

<http://www.interpretaciondelpatrimonio.com/boletin/index.php/boletin/article/view/24 3>. Acesso em: 02/04/2013.

MARTÍN, M. La memoria está llena de olvidos: Apuntes para una interpretación del Patrimonio en el Memorial los Merinales. Asociación para la Interpretación del Patrimonio, Sevilla, 30 jan. 2008. Disponível em:

<http://es.scribd.com/doc/5001315/Articulo-Canal-de-los-Presos>. Acesso em: 02/04/2013.

MILLER, G. A. The Magical Number Seven, Plus or Minus Two: Some Limits on Our Capacity for Processing Information. Psychological Review, n. 63. p. 81-96, 1956. 
MORALES, J. Guía práctica para la interpretación del patrimonio: el arte de acercar el legado natural y cultural al público visitante. Sevilla: Consejería de Cultura de la Junta de Andalucía, 2001.

MORALES, J.; GUERRA, F. Uso público y recepción en espacios naturales protegidos: la atención a los visitantes reales y potenciales. In: SEMINARIO PERMANENTE DE EDUCACIÓN AMBIENTAL EN ESPACIOS NATURALES PROTEGIDOS, Secretaría General de Medio Ambiente - M.O.P.T., Sevilla, 1996.

Disponível em:

<http://www.interpretaciondelpatrimonio.com/docs/docs/UsoPublico.pdf>. Acesso em: 02/04/2013.

MORALES, J.; GUERRA, F.; SERANTES, A. Bases para la definición de competencias en interpretación del patrimonio. In: SEMINARIO PERMANENTE DE INTERPRETACIÓN DEL PATRIMONIO, Centro Nacional de Educación Ambiental - CENEAM, Valsaín, 2009. Disponível em:

$<$ http://www.magrama.gob.es/es/ceneam/grupos-de-trabajo-y-seminarios/interpretaciondel-patrimonio-natural-y-cultural/anexo2_bases_competencias_interpr_tcm7-

13296.pdf>. Acesso em: 02/04/2013.

MOSCARDO, G.; BALANTYNE, R.; HUGUES, K. Designing Interpretative Signd: Principles in Practice. Colorado: Fulcrum Publishing, 2007.

MURTA, S.; ALBANO, C. Interpretar o patrimônio: um exercício do olhar. Belo Horizonte: UFMG/Terra Brasilis, 2002.

NATIONAL PARK SERVICE. Interpretive Development Program: Are You Connecting? Eppley Institute for Parks and Public Lands: Indiana University, 2007.

SERANTES, A. Interpretación del Patrimonio. Bases y recursos. In: VALES, C. (Org.) Manual de Gestión de Áreas Protegidas para los Países Lusófonos, CEIDA, A Coruña: CEIDA, 2010, p. 167-194.

SERANTES, A. Os centros de interpretación en Galicia: un recurso para o desenvolvemento turístico sostible? Ambientalmente sustentable, n. 11-12, p. 101$121,2011$.

SERREL, B. Exhibit labels: An interpretive approach. USA: AltaMira Press, 1996.

SUREDA, J. Interpretación del patrimonio: diseño de programas de ámbito municipal. Barcelona: UOC, 2008.

TILDEN, F. La interpretación de nuestro patrimonio. Tradução de Pablo Salas Rojas. 1. ed. Sevilla: Asociación para la Interpretación del Patrimonio, 2006. Titulo original: Interpreting our heritage.

TORRES, J. Consumo, luego existo: Poder, mercado y publicidad. Barcelona: Icaria, 2007. 
VEVERKA, J. Interpretive master planning. Montana: Falcon Press, 1994.

WEINSCHENK, S. Diseño inteligente: 100 cosas sobre la gente que todo diseñador necesita saber. Madrid: Anaya, 2011.

WIDNER, C.; WILKINSON, A. Conducting Meaningful Interpretation: A Field Guide for Success. Colorado: Fulcrum Publishing, 2006.

Recebido em: 05-02-2013

Aprovado em: 05-03-2013 